\title{
Lima: La indígena, la virreinal, la moderna -Muy breve historia urbana de la Ciudad de Los Reyes-
}

\author{
Lima: The indigenous, the viceregal, the modern \\ Very brief urban history of the City of Los Reyes
}

\author{
Adriana Scaletti Cárdenas ${ }^{2}$ \\ Pontificia Universidad Católica del Perú - Lima, Perú \\ https://orcid.org/0000-0002-8460-2206
}

\section{RESUMEN}

La historia de la ciudad de Lima es también la historia de su trazado y su tejido urbano. Desde el humilde asentamiento inicial, pasando por ensanches planificados con cuidado y orden, hasta la situación compleja y caótica del presente puede hablarse de una historia fisica particular y en muchos aspectos excepcional: reflejo y producto de la sociedad que la produjo, la antigua ciudad de Los Reyes permanece en la que puede percibirse hoy, de maneras cotidianas pero no por ello menos determinantes.

\section{Palabras clave}

Lima, historia de la arquitectura, ciudad, urbanismo, arquitectura

\section{ABSTRACT}

The history of the Lima city is also the history of its blueprint and its urban network. From the humble initial settlement, going through extensions planned with care and order, to the complex and chaotic situation of the present, we can speak of a particular physical history and in many aspects exceptional: a reflection and product of the society that produced it, the ancient city of Los Reyes remains as it can be perceived today, in many quotidian ways, but not for that less determining.

Keywords

Lima, history of architecture, city, urbanism, architecture.

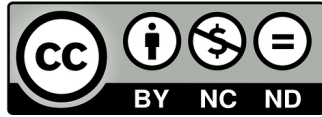

Cualquier uso que se haga de este artículo debe incluir: Autor / Título original de la publicación / ISSN.

1. Este texto se ha construido siguiendo el hilo conductor del libro de Oliver Perrottet (2017), Lima: una historia contada en planos (en prensa), en el marco de las actividades del grupo interdisciplinario de investigación Patrimonio Arquitectónico PUCP (PAPUCP) y con el apoyo de una Beca Grupal del Instituto Riva-Agüero de la Pontificia Universidad Católica del Perú.

2. Doctora en Historia del Arte y Gestión Cultural. ascaletti@pucp.pe. 
La ocupación del espacio en el territorio de lo que hoy llamamos la "Lima histórica" es, por supuesto, muy anterior a la fundación de la Ciudad de Los Reyes, la Lima "europea". Los especialistas entienden que existió un colectivo habitando el territorio del valle del Rímac y transformándolo desde por lo menos el año 200 antes de nuestra era: esta fecha se desprende del registro arqueológico de la construcción de una serie compleja de canales que aún permiten la vida en la ciudad, como famosamente son el Huatica, el Maranga o el Bocanegra, entre otros. Estos canales funcionaron en conjunto con otros sistemas de lo que hoy consideraríamos "infraestructura urbana", principalmente caminos y centros administrativos y religiosos de importancia como el complejo Maranga. La ocupación por la cultura Wari, unos 700 años después, dotó al valle de una ampliación del sistema de irrigación a partir de los grandes canales Surco y Ate, y la consolidación del monumental conjunto amurallado para el oráculo panandino de Pachacamac, en el valle vecino, frente al mar.

Posteriormente, el área de Lima fue ocupada en sucesión por los Chancay, los Chimú y los Incas. El dominio de estos últimos en toda la región -que se sostuvo por apenas unos 60 años- significó el potenciamiento de los sistemas de comunicación a través de un puente, un ramal del Qapac Nan -el "camino real" inca, conectando un área importante del continente- hacia la costa y el establecimiento de tambos y templos como el dedicado al Sol en el ya poderoso Pachacamac, además de centros ceremoniales como la huaca Mateo Salado y el oráculo local del Rímac.
Es, por tanto, posible hablar de un largo y trascendente proceso de colonización del territorio, determinante para el modelo de ciudad que a continuación establecerían sobre lo existente los españoles, y de muchas maneras igualmente determinante para la ciudad en que hoy vivimos.

La presencia española en el valle del Rímac comienza en 1533, con una expedición de avanzada a cargo de Hernando Pizarro -hermano mayor y capitán de Francisco Pizarro de Trujillo de Extremadura, Gobernador y Capitán General de la provincia del Perú, así como Alguacil Mayor y Adelantado- informa sobre el sitio al grueso de los conquistadores en términos muy positivos. Por tanto, poco después, se decide trasladar aquí la nueva capital virreinal desde Jauja en la sierra, con el objetivo de aprovechar tanto las bondades del valle cuanto la cercanía al mar como modo fundamental de contacto con España.

La fundación de la nueva ciudad se realiza el 18 de enero de 1535, en un área fuertemente marcada, como hemos ya mencionado, por canales y caminos tradicionales. Aunque no fueron considerados en la traza propuesta por Diego de Agüero -posiblemente dibujada físicamente en el terreno por Francisco Quinteros- resultaron determinantes en la lenta pero decidida deformación de la cuadrícula que los españoles proponían más o menos universalmente en su aventura americana; de modo que, sobre todo hacia las "afueras" del núcleo urbano original, estos se han perpetuado hasta el presente. Por otra parte, ya en la fundación oficial de la Ciudad de Los Reyes existieron divergencias frente al modelo considerado 
estándar $^{3}$ y que se asocia con las tardías Ordenanzas de Población (1573) de Felipe II, aunque ciertamente algo de las Leyes Nuevas (1542) de Carlos I fue respetado: un ejemplo clarísimo es la Plaza Mayor de la ciudad, alrededor de la cual se organizan los edificios de mayor importancia política y religiosa. No se encuentra en el centro preciso de la traza, sino prácticamente asociada al río Rímac, al considerarse de mayor importancia práctica tener el control del agua en el valle desde el nuevo palacio del gobernador Pizarro ${ }^{4}$ que seguir la norma al pie de la letra.

El Padre Bernabé Cobo y Peralta, S. J., en su Historia de la Fundación de Lima (ca. 1639), describe el plano de Agüero -hoy desaparecido- que conoció, y a partir de esta descripción se han realizado la mayor parte de reconstrucciones planimétricas de lo establecido entonces. Cobo indica la existencia de originalmente 116 manzanas cuadradas de 125 metros de lado $^{5}$ separadas por calles de 11 metros de ancho, además de la distribución de los solares -en cuartos de manzana-asignados por Pizarro a las órdenes religiosas y a los nuevos vecinos. Las tierras regadas por los canales Maranga y Huatica -cuya bocatoma y control se encuentran junto a la casa del Gobernador- fueron "distribuidas entre sus compañeros de armas, de acuerdo a los méritos en la conquista y al rango social de cada uno, mientras la mayoría de las congregaciones religiosas recibe tierras regadas por el río Surco" ". La futura catedral de Lima comenzó a construirse entonces, inicialmente como un edificio más bien modesto.

Pero esta no fue la primera iglesia de la ciudad: el título corresponde a la iglesia de la Merced, fundada como sencilla capilla un año antes de la ocupación del asentamiento como capital virreinal, por Miguel de Orenes y un grupo de mercedarios trabajando en el valle y el pueblo indígena desde 15337 . Estos mismos sacerdotes recibieron las tierras adyacentes al ramal del Qapac Nan que conducía a Armatambo y Pachacamac, y allí fundaron la hacienda Surquillo. Muy cerca, crearon además el pequeño pueblo indígena de San Miguel de Miraflores. Un poco más al sur, en el actual Chorrillos, se ubicó la encomienda de Antonio del Solar. Los Reyes siguió creciendo, lenta pero seguramente.

Al poco tiempo, se configuraron otros sectores destinados a usos y población más o menos diferenciados, como los Barrios Altos, el Cercado de Indios y San Lázaro "al otro lado del puente", por entonces una precaria estructura en madera. Sin embargo, si acaso existió una intención

3. Como comenta Gabriel BERNAT, "el texto de esta ley es en parte un compendio de las nociones teóricas en la cultura del tiempo y en parte el balance de una experiencia ya consolidada, por lo tanto describe un modelo útil en el plano operacional (dos ciudades argentinas ya realizadas -Mendoza en 1561 y San Juan de la Frontera en 1562- son virtualmente idénticas en las prescripciones de 1573)." Miami: 2002. Referencia obtenida en http://www. gabrielbernat.es/espana/leyes/odp/odp.html

4. Puede verse esto con claridad en planos como el publicado en la Estadística general de Lima de Manuel Atanasio FUENTES (Lima, 1858) y reproducido por BROMLEY y BARBAGELATA, entre otros.

5. Por supuesto, la cuantificación en metros es moderna, al utilizarse en ese momento las varas castellanas. Para el virreinato del Perú, cada vara correspondía aproximadamente a 83.5 centímetros.

6. Oliver PERROTTET. Lima: una historia contada en planos. Lima: en prensa, capítulo I.

7. Véase al respecto el texto de Reinhard AUGUSTÍN Burneo, El Damero de Pizarro. El trazo y la forja de Lima. Lima: Municipalidad de Lima, 2017, pp. 21-22. 
definida de segregar a determinadas clases sociales en barrios separados, ello nunca llegó a concretarse del todo ${ }^{8}$. En estos años se funda en la ciudad el primer hospital de españoles del continente, el Real Hospital de San Andrés en los Barrios Altos, muy cerca de la plaza y parroquia de indios de Santa Ana. Allí mismo, poco después, se fundó también el hospital de indios y más tarde aún el de negros, bajo la advocación de San Bartolomé. En 1551 se fundó la Real Universidad -hoy Universidad Nacional Mayor de San Marcos- primera y más antigua institución de su tipo en continuo funcionamiento en América. Luego, lentamente y tras muchos intentos fallidos por las crecidas del río, se construyó finalmente el Puente de Piedra en calicanto, que atraviesa de manera firme y segura el Rímac desde 1610.

Fray Buenaventura de Salinas y Córdova, sacerdote franciscano, escribió en 1630 un memorial instando a la corona española a promover la canonización de Francisco Solano, en el que describe la ciudad. Para Salinas y Córdoba, Lima era entonces la metrópolis y cabeza de todos los Reinos del Perú, con una situación geográfica envidiable -consideraba el cronista para ello el tema de su cercanía al mar, la ausencia de pantanos, la "limpieza de sus aires"- y una nutrida y diversa población, entre quienes se contaban a los virreyes, sus cortes y los más notables funcionarios del imperio español en América. Lima era, además, el mercado más importante de la región, centro de intercambio para una variedad de productos, y en general núcleo sudamericano de riqueza y poder. Por su parte, Fray Antonio de la Calancha, agustino, describió en esa misma década a Lima como una ciudad ordenada, simétrica y de rectas, anchas y largas calles; elementos que se establecieron ya en el plano de Agüero y que han permitido a algunos autores modernos la calificación de "ciudad renacentista"10. Poco después, la descripción de $\mathrm{Cobo}^{11}$ agrega a estas imágenes la de la nueva fuente en la plaza mayor, que reemplazaba en su ubicación a la picota, y las de las "calles en el aire" de los balcones "de cajón" con cerramientos de celosías que le daban a Lima un aire morisco y hermosas perspectivas.

Sin embargo, esta perfección idílica e idealizada presentada por los cronistas $^{12}$ debía atenerse a las consecuencias constructivas de los terremotos y temblores de la región: en general, la Lima española inicial -todavía muy acotada- era una ciudad "chata", con un tejido que solo raramente superaba los dos niveles $\mathrm{y}$ -puesto que no se daban lluvias ni nevadastechos uniformemente planos.

8. Véase al respecto OSORIO, Alejandra. Inventing Lima: BaroqueModernity in Peru's South Sea Metropolis. Hampshire: PalgraveMacmillan, 2008.

9. CALANCHA, Antonio de la. Coronica Moralizada del Orden de San Agustin en el Peru... Año de 1638 Con Licencia, en Barcelona Por Pedro Lacavalleria, en la calle de la librería. Transcripción, estudio crítico, notas bibliográficas e índices de Ignacio Prado Pastor. Lima: UNMSM, 1974-1981.

10. OSORIO, Alejandra. Op. Cit.

11. COBO Y Peralta, Bernabé. Historia de la Fundación de Lima. Colección de Historiadores del Perú. Obras inéditas o rarísimas e importantes, sobre la historia del Perú antes y después de la conquista. Volumen I. Lima: Manuel Gonzáles de la Rosa (editor), 1882 [1639].

12. Esto era, además, parte de un proceso de construcción conceptual de la ciudad de Lima como rica y poderosa capital virreinal. Al respecto, véase nuevamente OSORIO, Alejandra. Op. Cit. 
Los materiales utilizados en su construcción hablan de una larga tradición constructiva, incluso anterior a la ocupación europea: el adobe, usado en anchos muros sobre cimientos de piedra - con algunos muros importantes como los de las fachadas en ladrillo cocido- y la madera, para las cubiertas y entrepisos. Las iglesias y conventos, normalmente de envergadura más importante, utilizaron de manera más difusa el ladrillo y la piedra ${ }^{13}$. Cierto es, sin embargo, que la tecnología empleada necesitó importantes variaciones en el tiempo -algunas aprendidas de lo indígena, algunas adaptadas, algunas innovadoraspara enfrentarse y resistir a la problemática causada por la geografía de donde se emplaza la ciudad. Es quizá por ello que desde un inicio puede hablarse de Lima, como sugiere Bayón ${ }^{14}$, como de una ciudad en permanente reconstrucción.

Resulta, en ese sentido, emblemático el terremoto de 1746, el más grave que ha sufrido la ciudad. A las diez y media de la noche del 28 de octubre se desencadenó un evento que hoy se calcula de una magnitud de aproximadamente 8.6 en la escala de Richter, con una intensidad de X-XI en la escala modificada de Mercalli. Duró "tres credos" 15 , esto es, poco más de tres minutos. En un posterior testimonio, el Marqués de Ovando -Don Francisco José de Ovando y Solís- señaló que "no hay hipérbola que pueda expresar tanta tragedia en tan corto tiempo" $"$.

A este terrible terremoto, devastador más allá de toda previsión, le siguió apenas unos minutos después un no menos terrible tsunami, con olas de proporciones enormes que hicieron desaparecer completamente el vecino puerto del Callao, destruyendo una serie de naves que allí se encontraban ancladas, y penetrando hasta una legua por tierra hacia la ciudad ${ }^{17}$. La población de Lima, enormemente golpeada en cuanto a su infraestructura administrativa, material y de defensa, sobrevivió con grandes padecimientos a esta gigantesca catástrofe, aunque disminuida en más o menos 1200 personas. En el Callao, completamente

13. Véase al respecto a María Dolores CRESPO Rodríguez. Arquitectura doméstica de la ciudad de Los Reyes (15351750). Sevilla: CSIC, Universidad de Sevilla, Diputación de Sevilla, 2006.

14. BAYÓN, Damián. Sociedad y arquitectura colonial sudamericana. Una lectura polémica. Barcelona: Gustavo Gili, 1974, p. 67.

15. AGI (Archivo General de Indias), Lima 787. Desolación de la ciudad de Lima y diluvio del puerto del Callao. Cerrose esta relación en seis de noviembre de cuarenta y siete y sigue la calamidad que dará materia a la más larga explicación de los venideros sucesos. En Lima en la imprenta nueva que estaba en la calle de los Mercaderes- relación del capitán Victorio MONTERO, en 1746.

16. La carta en que Ovando relata estos eventos, con otras, se encuentra recopilada en Manuel DE ODRIZOLA (1863) Terremotos. Colección de las relaciones de los más notables que ha sufrido esta capital y que la han arruinado. Existen además testimonios semejantes desde todas las instancias de la sociedad: escribió, por ejemplo, el párroco de la iglesia de San Sebastián, al oeste de la Plaza Mayor que "Lima quedó hecha un corral sin ninguna casa donde habitar. Dios por su misericordia nos de la gracia y el tiempo para llorar" [Archivo Arzobispal de Lima. Parroquia de San Sebastián. Libro de bautizos de españoles (1733-1759). No. 5, f. 167v.]. Véase además LLANO Y ZAPATA, José Eusebio de. Carta ó diario que escribe D. Joseph Eusebio de Llano y Zapata, a su mas [sic] venerado amigo y docto correspondiente, el doctor Don Ignacio Chirivoga y Daza en que con la mayor verdad, y critica mas [sic] segura le dá [sic] cuenta de todo lo acaecido en esta capital del Perú, desde el viernes 28 de octubre de 1746... Madrid: imprenta de Juan de Zúñiga, 1748.

17. Véase PÉREZ-MALLAÍNA Bueno, Pablo Emilio. Retrato de una ciudad en crisis. La sociedad limeña ante el movimiento sísmico de 1746. Sevilla: CSIS, Escuela de Estudios Hispano Americanos; Lima: Pontificia Universidad Católica del Perú, Instituto Riva Agüero, 2001. También SILGADO, Enrique. Historia de los sismos más notables ocurridos en el Perú (1513-1974). Lima: Instituto de Geología y Minería, Boletín 3, enero 1978. 
destruido, sobrevivieron apenas un par de centenares.

Casi inmediatamente, el Virrey José Antonio Manso de Velasco - a quien luego, en reconocimiento de sus acciones frente a este desastre, se le otorgó el título de Conde de Superunda- y el consejo de la ciudad de Lima comenzaron sus trabajos por asegurar, junto con el restablecimiento del orden público, las necesidades básicas de agua y comida para la población luego tuvieron rápidamente que plantearse las posibilidades a futuro de la ciudad en cuanto estructura física ${ }^{18}$.

Se vio rápidamente que existían dos líneas de pensamiento al respecto entre los notables de la Ciudad de los Reyes llamados a deliberar: la reconstrucción de Lima con idéntica configuración a la original, la misma traza y en el mismo lugar; o el traslado de la ciudad a una región menos expuesta a los fenómenos sísmicos, con nuevas y más anchas calles. Se propuso como alternativa de nueva locación para el traslado, por ejemplo, el cercano valle de Lurigancho, hacia el este, al pie del cerro San Bartolomé ${ }^{19}$. Desde el siglo XXI, podemos permitirnos compadecer a estos antiguos vecinos que ingenuamente imaginaban que esa distancia sería suficiente para protegerlos de catástrofes que claramente se manejan a toda otra escala. Sin embargo, lo cierto es que esta bienintencionada prudencia, impulsada por científicos como el Cosmógrafo Mayor Luis Godin, finalmente no tuvo suficiente acogida entre los deliberantes.

\section{Godin sostenía:}

Es evidente que el País no permite edificio elevado ni construcción pesadas y las paredes sean de piedras, o de ladrillos, o de adobes, cuando todas ellas piden que en su naturaleza un cierto grueso se deben excusar sino se les da una considerable disminución de abajo a arriba de suerte que vaya este grueso de mayor a menor... El levantar torres en los templos es otra vez empezar a abrir sepulturas para los venideros de forma redonda; no es posible esperar se construyan con la solidez necesaria y sobre todo es preciso advertir que la cal de esta tierra no tiene la virtud competente de unirse con las materias de piedra o ladrillo... De ninguna de las maneras se permitirán Altos, ni aun de quincha, ni de bastidores, ni otra cosa más elevada, que el techo de la vivienda baxa el qual ha de ser de tixera... Asertado sería aislar todas las Casas, y construirlas todas de quincha en forma de un quadradoavierto, o cerrado dexando en el medio un Patio de bastante amplitud pero no tapado por la misma Casa aunque se callese, y alrededor otro Patio, que apartasse la Casa de la Pared de la Calle, y de la Cassa vecina, lo bastante para safarse de las

18. Toda la discusión posterremoto está ampliamente documentada en AGI, Lima 511.

19. No existe consenso entre los autores respecto al lugar oficialmente propuesto. Algunos, como Jorge BERNALES Ballesteros (Lima, la ciudad y sus monumentos. Escuela de estudios Hispano-Americanos de Sevilla. Sevilla, 1972, p. 308), sugieren que la zona elegida estaba en los llanos de la antigua hacienda El Pino (la zona del actual distrito de San Luis), en "las faldas del cerro San Bartolomé". Otros autores, como Isaac Sáenz (2007, p. 38), sugieren que la mudanza se propuso a un lugar más cercano del mismo valle de Lurigancho: Santa Inés. Este paraje está a unos 25 Km de Lima, mientras que el cerro San Bartolomé que menciona Walker (2008, p. 206) se encuentra definitivamente más alejado, a alrededor de $50 \mathrm{Km}$, siempre hacia el este de la capital virreinal. 
ruinas de una y otra. Pero pidiendo esta disposición en demaciado terreno no parece practicable... ${ }^{20}$.

El virrey necesitó de un segundo informe de idéntico, drástico tenor para convencerse de la necesidad de promulgar un bando a propósito. Lo hizo en enero de 1747, indicando que ninguna casa, ni sus cercas ni dependencias, debía superar las cinco varas un poco menos de cuatro metros y medio, es decir, el promedio interior de un primer nivel en las casas tradicionales limeñas; ordenaba la demolición inmediata de todos los pisos altos que se encontraran aún en pie e indicaba los materiales que era lícito utilizar.

Sus indicaciones dieron origen a una serie de pleitos con las familias más notables de la ciudad -encabezadas por los marqueses de Torre Tagle, los condes de Torre Blanca y los marqueses de Maenza- quienes veían en la ordenanza una disminución de sus privilegios de representación y estatus visible. No solo eso: se trataba también de un daño económico, pues desaparecidos los altos, tener que ocupar los bajos significaría una pérdida de alquileres importante. Finalmente, "perder altura significaba no sólo perder una parte de la vivienda, sino también el decoro que una familia principal necesitaba" ${ }^{21}$.
Abrumado, el virrey hubo de dar vuelta atrás aunque no sin quejarse privada $\mathrm{y}$ amargamente del egoísmo de los ricos limeños, que dieron al traste con su "convenientísima resolución... estimando en menos la seguridad de sus vidas y de sus compatriotas, que la vana ostentación de sus suntuosas fábricas o el despreciable interés que falsamente se prometen de sus arrendamientos..."; se debió disimular -término empleado por el propio virrey- la ordenanza para que todos los involucrados mantuvieran su dignidad y sus prebendas ${ }^{22}$. Lima, por tanto, continuó con edificios de más de una planta, aunque más flexibles y con altos en quincha ${ }^{23}$. Esa es la arquitectura virreinal que ha llegado hasta nosotros.

Algo que no ha permanecido, pero que en su momento fue determinante para la configuración morfológica de la ciudad, fue la muralla defensiva de Lima. Su construcción, bajo los auspicios del virrey Melchor de Navarra y Rocaful, duque de la Palata, se dio entre 1684 y 1687 para hacer frente a la posibilidad de invasiones de piratas y corsarios, aunque esta situación nunca se concretó en la realidad ${ }^{24}$. La muralla, cuyo trazado se determinó "sobre la marcha"25 -modificándose continuamente para derribar la menor cantidad de construcciones existentes- finalmente englobó mucho más de lo previsto en los

20. El texto completo se encuentra en Jorge BERNALES Ballesteros, Op. Cit., pp. 305-308.

21. CRESPO Rodríguez, María Dolores. Op. Cit., p. 55.

22. Véase AGI, Lima 415.

23. En el Perú, la quincha es un conjunto relativamente flexible y ligero conformado por barro emparedando pies derechos de madera o caña, con rellenos un poco más pesados -como ladrillo o adobe- en el tercio inferior y entramados de cañas más delgadas o madera partida amarradas con «huasca»-cuero húmedo que al secarse se contrae- en los dos superiores.

24. Sir Francis Drake llegó a costas peruanas en 1567. Le sucedieron franceses y holandeses; notablemente entre estos últimos puede contarse Jacob Clerk. Cuando apremia la construcción de la muralla de Lima en 1685, se reciben noticias del inglés Edward Davis arrasando puertos chilenos.

25. Véase al respecto el texto de Reinhard AUGUSTÍN Burneo, Op. Cit, p. 63. 
planes originales y se realizó en tierra cruda, con anchos parapetos y multitud de baluartes $^{26}$. De estos, en la Lima moderna subsiste apenas uno completo, muy cerca a la plaza del antiguo Cercado de Indios, en su momento parcialmente incluido dentro del área protegida.

La muralla es protagonista de muchos de los planos históricos que nos describen la ciudad, desde los del proyecto de la misma elaborado por Jean Raymond Coninck en 1682 hasta, famosamente, los dibujados por Pedro Nolasco en 1685 y 1687 que por su detalle y belleza estética han sido reproducidos innumerables veces, desde tan temprano como 174427. Aparece también en planos elaborados por viajeros europeos como el científico francés Amédée Frézier -el primero después de completada la muralla- al relatar su viaje entre 1712 y 1714. A pesar de este protagonismo, su papel se circunscribió al de límite urbano durante los siglos siguientes, en los que sobrevivió siendo incluso usada como muro de soporte para construcciones civiles adosadas.

El gobierno del virrey Manuel de Amat y Junient (1761-1776), de corte decididamente afrancesado e ilustrado, significó para la ciudad de Lima el inicio de una importante etapa de reformas urbanas: se trazaron el Paseo de Aguas, conectando con la gran Alameda de los Descalzos; se construyó la plaza de toros de Acho y se edificaron iglesias nuevas como Las Nazarenas, hogar del Señor de los Milagros ${ }^{28}$.

La ilustración como elemento de decisión urbana afectó Lima y en general todas las ciudades peruanas poderosamente a partir de ese momento: desde 1784, el virrey Teodoro de Croix emprendió una campaña de modernización del virreinato, comenzando con la descentralización de la administración al crear siete intendencias para todo el territorio de los dominios meridionales de España en América. En la capital, el nuevo intendente Jorge de Escobedo y Alarcón era el encargado de vigilar el orden y la seguridad públicas, para lo que organizó la división de la ciudad en cuatro cuarteles y cuarenta barrios, siguiendo el modelo implantado en la Metrópoli. Al tiempo, se realizaron modificaciones que permitieron prolongación de calles como el actual jirón Ancash, con la transformación de la iglesia de Nuestra Señora de la Peña Francia de Santa Clara. Además, las funciones del intendente involucraban el sistematizar la colocación de iluminación de casas, tiendas

26. La muralla terminada englobaba 920 hectáreas, atravesando el barrio del Cercado y dejando fuera al de San Lázaro, al otro lado del Rímac. Los muros eran de 5-6 metros de ancho, con 34 baluartes.

27. "Plano scenographico de la Ciudad de los Reyes, o Lima Capital de los Reinos del Perú", publicado por los viajeros Jorge JUAN y Antonio DE ULLOA en su libro Relación histórica del viage a la América Meridional. Se encuentra reproducido en PERROTTET, Oliver. Op. Cit.; JUAN y ULLOA produjeron también los primeros planos de Magdalena-Pueblo Libre, Miraflores y Surco (para el área que hoy es el distrito de Barranco).

28. El culto al Señor de los Milagros, también llamado el Señor de los Temblores, está relacionado sincréticamente con la devoción prehispánica al oráculo de Pachacamac -al punto de que se habla comúnmente del Cristo de Pachacamilla, por el origen de sus primeros seguidores trasplantados a Lima- y desde el terremoto de 1687 su procesión, cada vez más masiva, es tradicional en octubre. La fecha central de las actividades de culto es el 28 de octubre, en memoria del devastador terremoto de 1746, el peor que ha sufrido la ciudad de Lima. Véase a propósito a ROSTWOROWSKI (1992) Pachacamac y el Señor de los Milagros: una trayectoria milenaria. Lima: IEP, 1992. Complementariamente, véase también a Susy SÁNCHEZ (2002-2003, p. 81), "Un Cristo moreno "conquista" Lima: los arquitectos de la fama pública del Señor de los Milagros. 
y edificios públicos; tarea que, como el empedrado de calles, la canalización de acequias y la excavación de pozos para aguas servidas, se apoya en los aportes de los vecinos beneficiados con los nuevos servicios. En ese momento, se colocaron también azulejos con letreros que contenían el nombre oficial de la calle, se asignó numeración a más de ocho mil viviendas y se empadronaron calesas y carruajes de tracción animal (más de cuatro mil ${ }^{29}$ ). Con un espíritu similar, en 1785, el sacerdote franciscano Manuel Sobreviela recibió el encargo de sus superiores de elaborar mapas y planos de toda la intendencia a partir de su convento en Ocopa: el nuevo plano que elaboró de Lima resultó uno de los más detallados de la historia de la ciudad virreinal, incluyendo aspectos no representados en otros documentos contemporáneos, como la ubicación y nombre de todas las puertas en la muralla ${ }^{30}$, o la existencia hacia el este del pueblo de Lurigancho, que por tanto puede datarse a partir de este momento. En términos de representación cartográfica, la expedición científica Malaspina entre 1789 y 1794 cerró el siglo con un gran esfuerzo concentrado sobre todo en la configuración de la costa y sus puertos- que sin embargo debió ser corregido posteriormente por inexactitudes en cuanto a las mediciones instrumentales y que recibió duras críticas por parte de científicos contemporáneos como Von Humboldt.

El siglo XIX comenzó con la llegada a Lima en 1806 del nuevo virrey, José Fernando de Abascal. Una de sus preocupaciones principales fue el enfrentar las nuevas ideas independentistas, hijas tanto de los grandes cambios contemporáneos en el ámbito europeo como de la sostenida percepción de inequidad e injusticia de ciertos grupos americanos. Como parte de su política de asegurar apoyos de la elite local para la corona, Abascal realizó una serie de obras de importancia urbana, como la creación del Colegio de Medicina de San Fernando, el Jardín Botánico y el Cementerio General; este último -que necesitó la demolición de un sector de la muralla-desató controversia y desconfianza en la devota población de la ciudad, pero se consideró necesario en el marco de las ideas higienistas del momento.

En julio de 1821, el general independentista José de San Martín, tras infructuosas negociaciones con el último virrey José de La Serna, entró en Lima con sus tropas y declaró la independencia del país, desde la plaza mayor aún cubierta de tierra, sin pavimentar. La antigua Los Reyes es desde entonces capital de la República peruana, no sin sufrir durante toda la primera mitad del siglo un difícil período de caudillaje militar, ocupaciones de montoneros e incluso saqueos a grandes casas, tiendas y palacios. Entre 1821 y 1825, San Martín emitió, además, decretos que crearon formalmente el Departamento de Lima y sus provincias: Lima, Yauyos, Cañete, Ica y Huarochirí.

Dos décadas después, concretando planes a los que se aspiraba ya desde una convocatoria oficial en 1833, el gobierno del presidente Ramón Castilla implementó el primer ferrocarril del Perú y de Sudamérica: catorce kilómetros de

29. Véase PERROTTET, Oliver. Op. Cit., parte I.

30. Los puntos por los que se podía atravesar la muralla eran Martinete, Maravillas, Barbones, Cocharcas, Santa Catalina, Guadalupe, Juan Simón, Callao y Monserrate. 
línea férrea que conectaban la estación de Lima -en la actual plaza San Martín, tras haberse demolido para ello el antiguo convento y la iglesia de San Juan de Diosy la del Callao, ubicada detrás del fuerte Real Felipe, donde además se encontraban las oficinas de Aduanas. Se trató de un recorrido de gran popularidad cuyo costo se vio rápidamente amortizado: más de seis millones de personas lo utilizaron hasta 1860. En términos urbanos, esto favoreció además el desarrollo y prosperidad de los baños de La Punta, a través de la adición de un servicio de transporte de veraneantes en un carro de tracción animal desde la estación del Callao.

El éxito de la primera ruta llevó a planear y a la construcción de otro ramal que conectó Lima con los balnearios del sur: la estación final, terminada en 1858, se encontraba en Chorrillos -originalmente un pueblo habitado por pescadores y de humilde infraestructura, ya era entonces un punto favorecido por los ricos limeños para tomar baños de mar- con estaciones intermedias en Miraflores y Barranco. Este recorrido repetía el trazo del antiguo Qapac Nan hacia el sur.

Chorrillos creció enormemente con la implementación de esta conexión, haciéndose incluso necesaria una extensión de la misma hasta la antigua hacienda Villa. A las casas de pescadores, las haciendas y las casas de reposo se agregaron entonces numerosas nuevas viviendas, edificadas sobre todo por inmigrantes italianos, ingleses y franceses. La migración europea se asentó también en Miraflores, donde algunos ricos vecinos de Lima eligieron trasladar su residencia, llegando a contarse su población en 300 habitantes para mediados de siglo. En contraste, Barranco se mantuvo muy pequeño, y en planos como el elaborado por Luis Mariani en $1857^{31}$, continuó apareciendo apenas, indicándose sólo su iglesia.

Entre 1857 y 1859 , se oficializaron algunas de estas áreas ya urbanizadas como distritos, como parte de un proceso que se inicia para todo el país: se crean con esa categoría entonces Pueblo Libre (con el nombre tradicional de Magdalena Vieja), Chorrillos, Miraflores -con una extensión mayor a la actual, llegando hasta la muralla de Lima- y Lurín en el valle homónimo. El Callao fue, además, reconocido como Provincia Constitucional, un estatus especial que mantiene hasta el presente. La antigua Ciudad de Los Reyes, aún enmarcada por su muralla, se densificó y refinó sus espacios y edificios públicos y privados, según registró el plano elaborado por Manuel Atanasio Fuentes en 1858, donde aparecen 360 nombres de calles -en cada manzana cambiaba el nombre, como era tradicional- organizadas por barrios y cuarteles. En ese momento se realizaron, además, remodelaciones como las de la Alameda de los Descalzos, en la que se colocaron estatuas de mármol italiano representando los signos del zodíaco y los primeros faroles a gas de Sudamérica, superando el uso de los de aceite. La renovación tecnológica pasó también por el servicio de agua potable, con la

31. MARIANI, Luis. Plano Topográfico de los alrededores de Lima, 1857. Muestra todas las elevaciones de terreno, las haciendas y canales de riego, así como los ferrocarriles recién construidos. Señala además una línea Lima-Magdalena (hoy Pueblo Libre) que nunca llegó a construirse. Colección Gunther. Reproducido en PERROTTET, Oliver. Op. Cit., parte II. 
inauguración de la planta de tratamiento de agua de la Atarjea y el cambio de los conductos por nuevos de hierro, para abastecer a fuentes públicas e inmuebles particulares. En los años siguientes, se construyeron la nueva Penitenciaría Central de Lima -una estructura en panóptico-y el Mercado Central.

En 1861, la Municipalidad de Lima emitió un decreto con la intención de simplificar y modernizar la nomenclatura de las calles de la ciudad, uniformizando los nombres de las arterias en todo su recorrido en lugar de cambiar en cada manzana. Así, por ejemplo, la sucesión de las calles que comenzaban en el Puente de Piedra y se llamaban a partir de entonces Palacio, Portal de Escribanos, Mercaderes, Espaderos, La Merced, Baquíjano, Boza, San Juan de Dios, Belén y Juan Simón, hasta llegar a la penitenciaría y a la muralla, pasó a llamarse Jirón de la Unión. De forma similar, las calles a ambos lados de este eje pasaron a llamarse con nombres de Departamentos y ríos del Perú, y las que corren paralelas al mismo, con nombres de provincias, en un sistema conservado hasta hoy.

En 1868, el entonces presidente José Balta encargó al ingeniero estadounidense Henry Meiggs ejecutar un programa que permitiera la expansión de Lima-que por entonces contaba unos cien mil habitanteseliminando la muralla ese mismo año y construyendo en su lugar anchas avenidas y bulevares de estilo parisino. La influencia francesa fue importante en la ciudad, desde temas urbanos como las propuestas de Meiggs hasta la arquitectura e incluso las ciencias, al recibirse muchos ciudadanos $\mathrm{y}$ técnicos franceses y al intensificarse el accionar de comercios como la casa Dreyfus. En 1869, se construyó sobre el río Rímac el "puente nuevo", hoy llamado puente Balta, cuyo diseño en hierro también reconocía esta influencia francesa. Asimismo, debido a una crisis de salud pública en 1868 -una epidemia de fiebre amarilla- se hizo necesaria la construcción de un nuevo y más moderno hospital para la capital: con fondos de la Beneficencia Pública de Lima se edificó y habilitó entonces el hospital Dos de Mayo, de modelo radial con pabellones. Se ampliaron las conexiones férreas, de manera que para 1871 se contaba, además, con la de Lima-Callao y Lima-Chorrillos con Callao-Lima-La Oroya, Lima-Huacho y Lima-Magdalena.

Con motivo de conmemorarse el $50 .^{\circ}$ aniversario de la Independencia nacional, en 1872 se realizó una gran Exposición Nacional en el área al sur del núcleo urbano de la ciudad, apenas liberado del cerco de la muralla. Allí se mostraron una serie de productos peruanos e importados de países invitados, en el marco de una serie de pabellones organizados bajo la dirección de Manuel Atanasio Fuentes, de entre los que destacó como edificio principal el palacio neoclásico, prefabricado en piezas a partir de columnas de fierro, que hoy contiene el Museo de Arte de Lima. Se conservan también dos pabellones más pequeños en el parque: el presidencial y el morisco.

Como parte de la ampliación de la ciudad, siguiendo el Plan Regulador del ingeniero Luis Sada, en ese momento se planteó una nueva avenida paralela a la línea férrea hacia Chorrillos y al antiguo camino inca: esta vía, al tiempo la más ancha de Lima, permitió el desarrollo del nuevo barrio de La Victoria -llamada así por la huerta propiedad de Victoria Tristán, esposa del presidente Echenique- siendo nombrada 
posteriormente Paseo de la República. Además, se trazaron avenidas donde había sido la muralla, ya demolida: Perrottet argumenta que esto, al cortar el recorrido tradicional norte-sur prehispánico, marcó el inicio de un problema urbano aún no resuelto en cuanto a la circulación del tráfico ${ }^{32}$.

En 1881, la capital fue ocupada por las tropas chilenas como parte de las acciones de la Guerra del Pacífico, tras las batallas en las líneas de defensa de San Juan y Miraflores. Chorrillos y Barranco fueron incendiados y saqueados. El tratado en que se negoció la paz en 1883 y la consiguiente desocupación de la ciudad por parte del ejército de Chile se firmó en el elegante balneario de Ancón, establecido ya al norte de Lima. La recuperación de la ciudad y del país tomó décadas, en las que se vio por lo mismo muy limitado el crecimiento urbano de Lima; aunque numerosos refugiados desde las provincias del sur del país cedidas a los chilenos se establecieron a lo largo de la vía de conexión con el Callao, formando la urbanización Tarapacá.

Los progresos más notables logrados durante la década de los 80 , son el alumbrado eléctrico de la Plaza de Armas y de las calles adyacentes, inaugurado en 1886, que utiliza energía generada por una planta a vapor (por razones económicas, se apaga en las noches de luna), la implementación del servicio telefónico con el Callao, así como la fundación de varios planteles de educación (La Inmaculada, Santo Tomás, La Recoleta y otros). Según el censo de 1891, la población llega a 104
000 habitantes (47 600 blancos, 25400 mestizos, 18700 indios, 7500 negros y 4800 asiáticos) $)^{33}$.

Se cerró el siglo con la creación de los distritos de Santiago de Surco y Lurigancho, que incluye a la localidad de Chosica; pero también con la feliz formación de la Sociedad Geográfica de Lima y el Cuerpo Técnico de Tasaciones, con los que puede hablarse de un renacer de la cartografía urbana, tras los difíciles momentos de la posguerra.

En los planos y dibujos elaborados alrededor de la transición de los siglos XIX al XX, puede inmediatamente reconocerse a Lima como una ciudad que apenas ha cambiado desde 1650, no habiéndose realizado ninguna ampliación de importancia. Esto cambió definitivamente con los grandes proyectos de expansión del siglo XX, representados en planos como el "Proyecto de ensanche de la ciudad de Lima" elaborado por el ingeniero Enrique E. Silgado en 1899. En este documento, se graficaron la apertura de anchas avenidas y el desarrollo de nuevas urbanizaciones como Santa Beatriz o la expansión de Magdalena Vieja, Magdalena del Mar. Se configuró en ese momento la plaza Bolognesi, como núcleo de avenidas y como punto central de perspectiva visual, siguiendo todavía la influencia francesa de los bulevares de Haussmann en París. También, en 1899 se abrió la avenida Piérola, conectando Lima con la Magdalena tras la expropiación de terrenos de las haciendas Breña, Chacra Colorada, Azcona, Oyague, Desamparados y Orbea. Con el fin de facilitar procesos similares en el futuro, se dieron las leyes

32. PERROTTET, Oliver. Op. Cit., parte II.

33. PERROTTET, Oliver. Ibidem. 
de Expropiación Forzosa (1900) y de Apertura de Avenidas (1903). La conexión que se estableció en 1900 entre la plaza Bolognesi y la avenida Grau se nombró originalmente Nueve de Diciembre, en conmemoración de la Batalla de Ayacucho; pero tras la colocación de un monumento a Colón -anteriormente ubicado en el paseo de Acho- comenzó a llamársele popularmente Paseo Colón, denominación no oficial que ha perdurado hasta hoy. En estos años además se configuró el área del Barrio Chino alrededor de la calle Capón, un asentamiento ya importante desde el siglo anterior ${ }^{34}$.

En el plano de Santiago Basurco de 1904, apareció proyectada la gran avenida de la promotora La Colmena, dirigida por Nicolás de Piérola y algunos de los personajes más ricos del Perú de la época. Originalmente nombrada "avenida Interior" -aunque rápidamente se le conoció por el nombre de la empresa que la impulsó- partía de la plaza Dos de Mayo, atravesaba la llamada Huerta de la Virreina -antiguo sector rústico que durante años había cortado el desarrollo urbano- y llegaba en su primera etapa hasta la calle Arica (hoy Rufino Torrico). Basurco fue además el encargado de diseñar el colegio Guadalupe y la nueva Facultad de Medicina.

A pesar de este furor inmobiliario -y será precisamente la especulación urbana el motor más importante de la transformación citadina en el Perú desde ese momento y hasta hoy- la situación de los habitantes de Lima antigua no era la mejor en términos de servicios de provisión de agua y alcantarillado, sucediéndose con cierta frecuencia epidemias que preocuparon a las autoridades municipales: la más grave fue la peste bubónica, en Lima desde 1903 hasta 1905. Así, bajo el alcalde Federico Elguera (1901-1908) se renovaron prácticamente todos los servicios públicos y se instalaron muchos nuevos tendidos de agua $y$ desagüe, aunque podían observarse aún en uso los antiguos canales tradicionales de la ciudad $^{35}$.

En términos de transporte, un aporte importante se dio en 1906 con la creación -por la fusión entre la empresa de generación eléctrica Santa Rosa y las compañías de servicios de transporte existentes- de la Compañía del Ferrocarril Urbano de Lima Limitada (FCUL), que puso en marcha un plan de modernización: a las ya existentes líneas Lima-Callao, Lima-Magdalena y Lima-Chorrillos se les unieron unas nuevas para el servicio urbano, conectando Descalzos-Exposición, Monserrate-Cercado, Camal-Acequia de Islas y Malambito-Santa Rosa ${ }^{36}$. Entonces también se realizó la parcelación de los antiguos fundos Manzanilla y Santa Cruz -aprovechando el trazado de la nueva avenida del Ejército- y se potenciaron

34. Desde 1899 la migración asiática también incluirá a los japoneses, muy numerosos en la ciudad.

35. En planos como el "Plano de Lima: Trabajos de canalización y saneamiento" dibujado por Julio E. Ribeyro en 1904 (Colección Gunther, Perrottet, Oliver. Op. Cit.). Del mismo año, también resulta de interés el "Plano de Lima, con indicación de los lugares donde se han presentado ratas y pericotes muertos", elaborado por Luis Guillermo Velarde, aprobado por Juan B. Agnoli (Colección Gunther, Perrottet, Oliver. Op. Cit.).

36. Perrottet señala que en ese momento, “Al mismo tiempo que se comienza a visualizar el triángulo Lima - Callao Chorrillos como espacio urbano metropolitano, la mirada de los especialistas se dirige más allá, con el fin de conocer los alrededores de la futura ciudad. Esta preocupación se refleja, en primer lugar, en la elaboración de los primeros planos que muestran - con curvas de nivel - , la topografía real del valle del río Rímac, abastecedor de agua potable de la ciudad". PERROTTET, Oliver. Op. Cit., parte 3. 
los balnearios de Barranco, Chorrillos, Miraflores y Ancón, con La Punta como nuevo espacio "de moda".

El segundo gobierno de Augusto B. Leguía marcó definitivamente la transición entre la Lima antigua y la moderna: el llamado oncenio (1919-1930) resultó además determinante en su modificación de lo social, económico y político hacia las bases del Perú contemporáneo. Solamente en cuanto a lo urbano, se dictaron leyes de capital importancia, como las de nuevas avenidas (1920), regulación de los suburbios (1922) o la de inspecciones técnicas para nuevas habilitaciones urbanas (1924). Al mismo tiempo, se manifestó con fuerza la migración de grandes grupos de población del campo a las ciudades, en particular Lima, buscando una mejor calidad de vida. La posibilidad de transporte motorizado -ya el tranvía o el ferrocarril, ya el novísimo automóvilpermitió, además, expandir seriamente los límites de la ciudad habitable y pensar más allá de la dimensión contenida del asentamiento tradicional: apareció la idea de la "ciudad jardín", hecha de chalets aislados, rodeados de verde, en un modelo de amplio alcance que finalmente llevó a la conurbación de espacios antes separados en la nueva gran y metropolitana Lima.

La ciudad antigua, a la que antes uno se refería como "Lima", comienza a llamarse "el Centro", núcleo de una Lima extendida. Alrededor de este Centro se observa una intensa actividad constructora. Numerosas obras públicas son ejecutadas con la participación de empresas norteamericanas, entre ellas The Foundation Company y la Fred E. Levy \& Co., a cuya sombra nacen las primeras empresas constructoras peruanas.

En la periferia de la ciudad, se construyen el Hospital Arzobispo Loayza (terminación de la obra); el Hospital del Niño; el Museo de Arte Italiano (obsequio de la colonia italiana); el Ministerio de Fomento y Obras Públicas, proyectado por Eduardo Malachowski y construido por la Foundation Company; el Estadio Nacional, en el terreno obsequiado por la colonia inglesa; el Club Lawn Tennis, así como los colegios AngloPeruano, Raimondi y La Salle. Siendo aficionado a la hípica, Leguía cede al Jockey Club los terrenos para la ampliación del hipódromo de Santa Beatriz $^{37}$.

El gobierno de Leguía coincidió con la conmemoración del centenario de la Independencia del Perú ${ }^{38}$. Se recibieron donaciones y obsequios de las principales colonias extranjeras en el país, muchos de ellos en la forma de espacios públicos u objetos de ornato urbano, como el reloj del parque universitario, regalo de la colonia alemana. En este trance también se demolió la estación de ferrocarril de San Juan de Dios, y en su lugar se construyó la plaza San Martín: en su lado oeste se edificó el gran hotel Bolívar, el primero de lujo en la ciudad.

37. PERROTTET, Oliver. Op. Cit., parte 3.

38. Véase al respecto a HAMANN, Johanna. Leguía, el Centenario y sus monumentos. Lima: 1919-1930. Lima: Pontificia Universidad Católica del Perú, Fondo Editorial, 2015. 
En la primera mitad del siglo XX, la expansión más importante de Lima se produjo hacia el balneario de Miraflores, a través de la nueva avenida Leguía, hoy avenida Arequipa. Alrededor de esta vía se crearon entonces las nuevas urbanizaciones de Santa Beatriz, Lince y Lobatón; el potenciamiento que la avenida dio a Miraflores significó que promotores inmobiliarios como Tomás Marsano dueño de la hacienda Surquillo-se interese por la lotización de sus terrenos, haciendo del antiguo balneario un lugar estimado por las elites limeñas: el propio presidente de la república tuvo allí su residencia, y creando el distrito de Surquillo. En 1920 ya se había creado la Compañía Urbanizadora San Isidro, que se ocupó de la habilitación de un barrio exclusivo alrededor del viejo bosque El Olivar, de origen virreinal, en un fundo propiedad de los condes de San Isidro. En el límite oeste del nuevo barrio se construyeron el Lima Golf Club, el Country Club y, a partir de 1924, las urbanizaciones Orrantia y Country Club. Para acceder a esta zona, se trazaron las avenidas Javier Prado y Pershing, seguidas por la Brasil y la ampliación hacia el Callao de Pershing, llamada La Marina. Aparecieron además en este momento los primeros autobuses metropolitanos, como también las escuelas Militar y de Aviación de Las Palmas. En las faldas del Morro Solar de Chorrillos, sobre los restos del antiguo asentamiento precolombino, se formó en 1928 la primera barriada de Lima: Armatambo.

El período urbanizador intenso de Leguía se frustró por una causa externa: el "crack" de la bolsa de 1929. Esto significó la pérdida del valor de las exportaciones de las materias primas, y con ello la caída de la popularidad y el poder del presidente, que fue apresado y pasó sus últimos días en cautiverio. A esto siguió un período de consolidación de lo ya edificado, aunque el continuo aumento de la población ${ }^{39}$ obligó rápidamente a las nuevas autoridades $\mathrm{a}$ tomar medidas importantes.

A partir de 1935 y hasta por lo menos 1955, la ciudad construyó los llamados Barrios Obreros y luego las Unidades Vecinales. Los primeros, destinados como su nombre lo indica a las clases trabajadoras, se realizaron inicialmente en el Rímac y en La Victoria, con algunos ejemplos significativos en lo que hoy es el distrito de San Martín de Porres. Las segundas, concebidas como "ciudades en miniatura", buscaban albergar a entre 1000 y 5000 personas cada una, en zonas cercanas a fábricas y centros de producción, en las afueras de la ciudad tradicional. Cada una, organizada en bloques de departamentos, se apoyaba en escuelas, comercios, servicios recreativos, deportivos, cívicos y religiosos, de manera que se trataba de unidades - por lo menos tentativamente- autosuficientes. Barrios Obreros y Unidades Vecinales, absorbidos por la gigantesca metrópolis capitalina, sobreviven hasta hoy aunque en muchos casos habiendo sufrido degrado y transformaciones importantes.

En 1940, hacia el mediodía del día 24 de mayo, se produjo un fuerte movimiento sísmico centrado en Lima y el Callao, acompañado por un tsunami. El temblor, registrado como de $8.2 \mathrm{Mw}$ fue el segundo más intenso sentido en la capital después del de 1746 y el más importante del siglo

39. La población del área metropolitana de Lima llegó, según el Censo General de 1940, a 577,000 habitantes. En comparación con el censo de 1920 , la tasa del crecimiento poblacional había subido de $2.8 \%$ a $6.5 \%$. 
XX: se contaron alrededor de 180 muertos y más de 3500 heridos solo en Lima, mientras el Callao se vio disminuido en 100 personas, con unas 2000 reportadas heridas. Muchas edificaciones históricas, entre ellas las iglesias de San Agustín, La Merced y San Francisco sufrieron graves agrietamientos y colapsos parciales.

Los meses posteriores al terremoto no resultaron menos destructores, aunque por motivos diferentes: con la idea de completar un proyectado anillo vial que canalizara ordenadamente el tráfico automovilístico en el centro histórico, se decidió la ampliación y apertura de anchas avenidas que atravesaron el mismo, destruyendo en el proceso una serie de edificios de valor patrimonial:

Por el ensanche del jirón Abancay, sufren el convento y la iglesia de Santa Teresa, el Colegio San Pablo de la Compañía, y en forma parcial los conventos de la Concepción y San Francisco. Al convertir el jirón Tacna en avenida se sacrifican la iglesia de Santa Rosa, el antiguo hospital de marineros del Espíritu Santo y, parcialmente, el convento de las Nazarenas, mientras la continuación de la avenida Bolivia borra del mapa a la iglesia de Belén, antigua Recoleta Mercedaria ${ }^{40}$.

A estas construcciones conocidas deben agregarse muchas casas de los siglos XVII, XVIII y XIX, víctimas privadas de un proceso que no trajo ningún beneficio inmediato y que continúa inacabado.

Desde la década de 1940 y -podría argumentarse- hasta el presente, el crecimiento de la ciudad de Lima se ha dado en dos vertientes: por un lado, las ampliaciones y expansiones formales, y por otro, la ocupación informal de terrenos, luego lentamente habilitados por sus ocupantes. Ya en 1942, se registra una primera ocupación de tierras a gran escala cerca de la fábrica de Atocongo: la comunidad Poeta José Gálvez, por familias provenientes de Pachacámac, Lurín y otras partes de Lima. En los años siguientes, no siempre de forma pacífica, se invadieron tierras agrícolas en la margen derecha del río Rímac, o alrededor del nuevo Mercado Mayorista (inaugurado en 1945), o en los cerros San Cosme, El Agustino o San Cristóbal.

El gobierno de Manuel Odría, entre 1948 y 1956, coincidió con la guerra de Corea y por tanto con el aumento de las exportaciones peruanas. Ello permitió que se pudieran ejecutar algunas importantes obras públicas, como los Ministerios de Educación, de Trabajo y de Salud Pública; el Hospital Militar, el Hospital Central del Seguro Social del Empleado (hoy Rebagliati) y el Centro Médico Naval; el Estadio Nacional (en el terreno donado por la colonia inglesa en el Perú, sobre el centro administrativo prehispánico más importante de la costa, Maranga) y diversas Grandes Unidades Escolares.

Sin embargo, el momento fue también de un aumento poblacional explosivo para la capital, lo que llevó a un período de ocupaciones e invasiones de terrenos agrícolas y eriazos sin precedentes, en un fenómeno que se perpetuó intensamente hasta la década de 1980: por ejemplo, en 1954 familias provenientes de diversos 
distritos de Lima llegaron a los arenales ubicados al lado izquierdo de la antigua carretera a Atocongo y constituyeron allí la barriada llamada Ciudad de Dios; la quebrada vecina a Quebrada Honda es ocupada en 1956 por la asociación de familias "El Triunfo"; en 1958, unas 10000 personas participan en la invasión de los cerros eriazos del área de Comas; etc.

Al construirse el puente Santa Rosa para prolongar la avenida Tacna hacia el distrito del Rímac en 1960, un grupo de pobladores es desalojado de las orillas del río, y reubicado en la zona de El Triunfo, por intervención de María Delgado de Odría, esposa del ex-presidente, quien luego presta apoyo a la creación de un nuevo distrito en el lugar. Como muestra de gratitud, los fundadores optan por agregar su nombre al de la nueva jurisdicción que nace al año siguiente como Villa María del Triunfo. En los años siguientes, alrededor de Ciudad de Dios se van formando entre otros, los asentamientos de Pamplona Baja y Alta, así como la extensa urbanización San Juan, subdividida en cinco zonas ${ }^{41}$.

Eventualmente, muchas de estas barriadas se formalizan e incluso constituyen nuevos distritos, como El Agustino y años más tarde, Villa El Salvador.

El gobierno del presidente Fernando Belaúnde Terry continuó con la política de construcción de conjuntos habitacionales: entre 1963 y 1968, se construyeron las residenciales multifamiliares San Felipe y Santa Cruz, orientadas a la clase media, y Condevilla Señor y Caja de Agua, más populares. Además, se dieron los pasos preliminares para los proyectos PREVI (Proyectos Experimentales de Vivienda), llegándose a terminar más del $55 \%$ de todas las viviendas de construcción estatal de la época republicana del país ${ }^{42}$.

A partir de 1967, se comenzó la excavación para la nueva Vía Expresa-que la población de Lima bautizó como "el zanjón"- desde la plaza Grau en el centro hasta Barranco. Esta intervención, muy celebrada por los poseedores de automóviles de la ciudad, constituyó sin embargo un problema desde el inicio en cuanto significó el acceso de más vehículos a las estrechas calles del centro histórico.

En 1970, bajo el gobierno militar de Juan Velasco Alvarado, la ciudad contaba ya con casi tres millones de habitantes: ya era "la Gran Lima", y las zonas periféricas al norte, al sur y al este -los "conos"- continuaron creciendo rápidamente. Esta década y las dos siguientes se vieron marcadas por el total descontrol tanto del crecimiento urbano como del transporte público, a lo que se unió la degradación y decadencia, al mismo tiempo tugurización y abandono de los edificios del centro de la ciudad antigua.

Los años 80 del siglo $\mathrm{XX}$, estuvieron en gran parte definidos por el terrorismo y el conflicto político interno. La ciudad de Lima, acostumbrada ya a las invasiones, vio incrementadas estas al migrar forzosamente grupos importantes de población huyendo de la violencia en otras regiones del país.

41. PERROTTET, Oliver. Ibidem.

42. OSTERLING, Jorge. 1982. "La problemática de la vivienda en Lima. Algunas políticas de vivienda estatal”, en Socialismo y Participación, n. 19, p. 14. 
Esto significó la pérdida de áreas verdes y agrícolas, y el aumento del desenfreno en el tráfico, a pesar de intentos de ordenamiento y proyectos suspendidos como el del tren elevado, el "tren eléctrico". Los atentados contra espacios y edificios públicos se volvieron moneda corriente, y la falta esporádica de corriente eléctrica por la voladura de las torres de alta tensión en los cerros vecinos a la capital sumió a la población en una situación de inseguridad y terror que se perpetuó hasta mediados de la década de 1990. Con todo ello, en 1991 y gracias al esforzado trabajo de organismos como el Patronato de Lima, UNESCO declara al centro de la ciudad como Patrimonio Mundial. Campañas para la recuperación del espacio tradicional se inician entonces, incluyendo una que invita a la población de más recursos a "adoptar un balcón", con cierto éxito.

El cambio de milenio significó la apertura del país -y con ello, importantemente de Lima- a los capitales internacionales. Esto involucró la apertura de grandes centros comerciales, estaciones de gasolina y servicios, y la densificación de áreas como Miraflores, San Isidro y La Molina. Asimismo, se hicieron los primeros intentos de ordenar el caótico transporte público con servicios como el Metropolitano, un sistema de autobuses rápidos en una línea dedicada siguiendo el trazado del "zanjón". El centro histórico de la ciudad, todavía en situación muy precaria a pesar de los esfuerzos, sobrevivió al deterioro aunque no puede hablarse de ninguna manera de un espacio recuperado. Incendios de importancia, temblores y terremotos, el abandono, la desidia, la corrupción, siguen siendo los peores enemigos de la antigua Ciudad de Los Reyes de Lima.

Lima, antigua sede de las clases criollas dominantes que vivían a espaldas -y a expensas- del resto del país, es ahora una gran ciudad de extraños. Gente proveniente de todos los rincones del país, de distintas lenguas y culturas, se amalgama en busca de un nuevo tipo de colectividad urbana. Formas de solidaridad y reciprocidad, de comercio, industria y artesanía, de asociación en clubes departamentales o de madres, y en ollas comunes, así como las festividades, cultos, comidas y música de origen campesino se han refundido, convirtiéndose en expresiones propias de la Lima de hoy ${ }^{43}$.

Decía Abraham Valdelomar: "El Perú es Lima, Lima es el Jirón de la Unión, el Jirón de la Unión es el Palais Concert y el Palais Concert soy yo". La ciudad, es verdad, es reflejo y consecuencia de sus habitantes. Nuestro trabajo es pensar en qué reflejo queremos, y cómo podemos lograrlo. 


\section{REFERENCIAS}

Archivo General de Indias (AGI). Lima, 415. El virrey del Perú al rey. Lima, 17 de abril de 1747.

Archivo General de Indias (AGI): Lima, 511. Varios documentos relativos a la posibilidad de traslado y a la reconstrucción de la ciudad de Lima, entre ellos Memorial del doctor don Manuel de Silva y La Banda dirigido al Real Acuerdo- Lima, 29 de mayo de 1747; y Testimonio de los autos obrados sobre el arreglamiento de la nueva reedificación de las casas de Lima- Lima, 15 de junio de 1748.

Archivo General de Indias (AGI): Lima, 787. Desolación de la ciudad de Lima y diluvio del puerto del Callao. Cerrose esta relación en seis de noviembre de cuarenta y siete y sigue la calamidad que dará materia a la más larga explicación de los venideros sucesos. En Lima en la imprenta nueva que estaba en la calle de los Mercaderesrelación del capitán Victorio MONTERO, en 1746.

Augustín Burneo, Reinhard. (2017). El Damero de Pizarro. El trazo y la forja de Lima. Lima: Municipalidad de Lima.

Bernales Ballesteros, Jorge. Lima, la ciudad y sus monumentos. Sevilla: Escuela de Estudios Hispano-Americanos de Sevilla, CSIC, 1972.

Bernat, G. (2002). Ordenanzas de descubrimientos, nueva población y pacificación de las Indias (1573). Miami. Recuperado de http://www.gabrielbernat.es/espana/leyes/odp/ odp.html

Bromley, Juan. (1945). Evolución Urbana de Lima. Lima: Editorial Lumen.

Calancha, Antonio de la. Coronica Moralizada del Orden de San Agustin en el Peru... Año de 1638 Con Licencia, en Barcelona Por Pedro Lacavalleria, en la calle de la librería. Transcripción, estudio crítico, notas bibliográficas e índices de Ignacio Prado Pastor. Lima: UNMSM, 1974-1981.

Cobo, Bernabé. Historia de la fundación de Lima. Colección de Historiadores del Perú. Obras inéditas o rarísimas e importantes, sobre la historia del Perú antes y después de la conquista. Volumen I. Lima: Manuel Gonzáles de la Rosa (editor), 1882 [1639].

Crespo Rodríguez, María Dolores. Arquitectura doméstica de la Ciudad de los Reyes (1535-1750). Sevilla: CSIC, Universidad de Sevilla, Diputación de Sevilla, 2006.

De Odrizola, Manuel. Terremotos. Colección de las relaciones de los más notables que ha sufrido esta capital y que la han arruinado. Lima, 1863.

Llano y Zapata, José Eusebio de. Carta ó diario que escribe D. Joseph Eusebio de Llano y Zapata, a su mas venerado amigo y docto correspondiente, el doctor Don Ignacio Chirivoga y Daza en que con la mayor verdad, y critica mas segura le dá cuenta de todo lo acaecido en esta capital del Perú, desde el viernes 28 de octubre de 1746... con el grande movimiento de tierra que padeció á las diez y media de la noche del mencionado dia hasta 16 de febrero de 1747: con una tabla en que se sá el calculo exacto de todo el numero de temblores... Madrid: imprenta de Juan de Zúñiga, 1748 
[Versión digitalizada, Biblioteca Digital Hispánica, http://bdh-rd.bne.es/viewer. vm?pid=d-3472084].

Osterling, Jorge. "La problemática de la vivienda en Lima. Algunas políticas de vivienda estatal", en Socialismo y Participación, n. 19.

Osorio, Alejandra B. (2008). Inventing Lima. Baroque Modernity in Peru's South Sea Metropolis. New York: Palgrave Macmillan.

Pérez Mallaína Bueno, Pablo Emilio. (2001). Retratro de una ciudad en crisis: la sociedad limeña ante el movimiento sísmico de 1746. Sevilla: CSIC - Escuela de Estudios Hispano-Americanos; Lima: PUCP, Instituto Riva-Agüero.

Perrottet, Oliver. (2017). Lima: una historia contada en planos. Lima: manuscrito.

Rostworowski, María. (1992). Pachacamac y el Señor de los Milagros: una trayectoria milenaria. Lima: IEP.

Sánchez, Susy. "Un Cristo moreno "conquista" Lima: los arquitectos de la fama pública del Señor de los Milagros (1651-1771)"; en Carrillo S.; O'phelan, S. (Comp.) Etnicidady discriminación racial en la historia del Perú. Lima: PUCP - Instituto Riva-Agüero Banco Mundial, 2002-2003.

Sáenz, Isaac. "Eventos sísmicos e intervención urbana en Lima tardo virreinal"; en Revista del Colegio de Arquitectos del Perú, Lima №5 Año 1, Setiembre-Octubre 2007.

Silgado, Enrique. (1978) Historia de los sismos más notables ocurridos en el Perú (15131974). Lima: Instituto de Geología y Minería, Boletín 3, enero .

Walker, Charles. (2008) Shaky colonialism: the 1746 earthquake-tsunami in Lima, Peru, and its long aftermath. Durham: Duke University Press.

Fecha de recepción: 20 de enero de 2020

Fecha de aceptación:18 de marzo de 2020 